\title{
Extracellular Hypotonicity Induces Disturbance of Sodium Currents in Rat Ventricular Myocytes
}

\author{
L. HU, J. MA, P. ZHANG, J. ZHENG
}

Cardio-Electrophysiological Research Laboratory, Medical College, Wuhan University of Science and Technology, Wuhan, People's Republic of China

Received September 28, 2008

Accepted November 27, 2008

On-line December 17, 2008

\begin{abstract}
Summary
Hypotonic solution alters ion channel activity, but little attention has been paid to voltage-dependent sodium channels. The aim of this study was to investigate the effects of hypotonic solution on transient sodium currents $\left(\mathrm{I}_{\mathrm{NaT}}\right)$ and persistent sodium currents $\left(I_{\text {NaP }}\right)$. We also explored whether the intracellular signal transduction systems participated in the hypotonic modifications of sodium currents. $I_{\mathrm{NaT}}$ and $\mathrm{I}_{\mathrm{NaP}}$ were recorded by means of whole-cell patch-clamp technique in isolated rat ventricular myocytes. Our results revealed that hypotonic solution reduced $I_{\mathrm{NaT}}$ and simultaneously augmented $\mathrm{I}_{\mathrm{NaP}}$ with the occurrence of interconversion between $\mathrm{I}_{\mathrm{NaT}}$ and $\mathrm{I}_{\mathrm{NaP}}$. Hypotonic solution shifted steady-state inactivation to a more negative potential, prolonged the time of recovery from inactivation, and enhanced

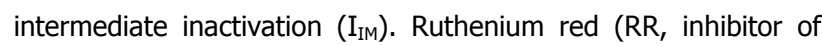
TRPV4), bisindolylmaleimide VI (BIM, inhibitor of PKC), Kn-93 (inhibitor of $\mathrm{Ca} / \mathrm{CaMKII}$ ) and BAPTA ( $\mathrm{Ca}^{2+}$-chelator) inhibited the effects of hypotonic solution on $I_{\text {NaT }}$ and $I_{\text {Nap. Therefore we }}$ conclude that hypotonic solution inhibits $\mathrm{I}_{\mathrm{NaT}}$, enhances $\mathrm{I}_{\mathrm{NaP}}$ and $\mathrm{I}_{\mathrm{IM}}$ with the effects being reversible. TRPV4 and intracellular $\mathrm{Ca}^{2+}$, PKC and $\mathrm{Ca} / \mathrm{CaMKII}$ participate in the hypotonic modifications of sodium currents.
\end{abstract}

\section{Key words}

Hypotonic solution - Ventricular myocytes • Sodium channels • Whole-cell recording $\bullet$ Signal transduction systems

\section{Corresponding author}

J. Ma, Cardio-Electrophysiological Research Laboratory, Medical College, Wuhan University of Science and Technology, No. 947 Heping Avenue, Qingshan District, Wuhan, 430081, China. Fax: +86-27-68862109. E-mail: mjhua@wust.edu.cn

\section{Introduction}

Extracellular hypotonic solution alters the electrical activity of excitable cells, which is a frequent pathological condition in many cases as ischemia, hypoxia, intoxication, infection, water and electrolyte metabolic disorders. Hypotonic cell swelling can cause arrhythmia and other heart disorders (Kawata et al. 1974, TranumJensen et al. 1981, Jennings et al. 1986, Janse and Wit 1989, Vandenberg et al. 1996, Diaz et al. 2003, Kocic 2005). Many studies have reported that hypotonic cell swelling modulates several ion channels, ion exchangers or ion transporters (Vandenberg et al. 1996, Kocic et al. 2001, Mongin and Orlov 2001). For instance, hypotonic solution provoked a kind of outward rectifying chloride current $\left(\mathrm{I}_{\mathrm{cl}}\right.$ swell $)$ in canine atrial myocytes which participated in regulatory volume decrease (RVD) (Sorota 1992, Hiraoka et al. 1998). While many studies focus on $\mathrm{Cl}^{+}$or $\mathrm{K}^{+}$channels and on $\mathrm{Na}^{+} / \mathrm{K}^{+}$ATPase, little attention has been paid to hypotonicity-induced effects on voltagedependent sodium channels (Sorota 1992, Vandenberg et al. 1996, Wang et al. 2005). Being responsible for the rapid upstroke of action potential, voltage-dependent sodium channels play important roles in the activities of myocardial excitability and conduction (Goldin 2002). The disorder of sodium currents contributes to ischemia, arrhythmia, cardiac failure and other acquired cardiac dysfunctions (Ju et al. 1996, Antzelevitch and Belardinelli 2006, Saint 2006, Song et al. 2006, Luo et al. 2007, Wang et al. 2007). Consequently, the study of hypotonicityinduced effects on the voltage-dependent sodium channels in ventricular myocytes is significant for understanding the mechanisms of cardiac dysfunctions. 


\section{Methods}

\section{Solutions and drugs}

The calcium-free Tyrode solution contained (in mmol/l): $\mathrm{NaCl} 135, \mathrm{KCl} 5.4, \mathrm{MgCl}_{2}$ 1, $\mathrm{NaH}_{2} \mathrm{PO}_{4}$ 0.33, HEPES 10, glucose $10(\mathrm{pH}$ 7.4). The $\mathrm{KB}$ solution contained (in mmol/l): $\mathrm{KOH} 70, \mathrm{KCl} 40, \mathrm{MgCl}_{2} 3$, $\mathrm{KH}_{2} \mathrm{PO}_{4}$ 20, EGTA 0.5, L-glutamic acid 50, taurine 20, HEPES 10, glucose 10 (pH 7.4). For whole-cell current recording, the intracellular pipette solution contained (in mmol/l): $\mathrm{CsCl} 120, \mathrm{CaCl}_{2}$ 1, $\mathrm{MgCl}_{2}$ 5, $\mathrm{Na}_{2} \mathrm{ATP}$ 5, TEA 10, EGTA 11, HEPES 10 (pH 7.3).

In this research, transient sodium currents $\left(\mathrm{I}_{\mathrm{NaT}}\right)$ and persistent sodium currents $\left(\mathrm{I}_{\mathrm{NaP}}\right)$ were recorded simultaneously to reveal the correlation between them. Thus we made the $\left[\mathrm{Na}^{+}\right]$concentration as $65 \mathrm{mmol} / \mathrm{l}$ in the extracellular bath solution which contained (in mmol/l): $\mathrm{NaCl} 65, \mathrm{CsCl} 23, \mathrm{KCl} 5, \mathrm{MgCl}_{2} 1, \mathrm{CaCl}_{2} 2$, HEPES 10, glucose 10, mannitol 96, (300 mOsm $/ \mathrm{kg}$ or $300 \mathrm{M}$ isotonic solution, $\mathrm{pH} 7.4$ ). For the $280 \mathrm{M}$ and $260 \mathrm{M}$ hypotonic solution, mannitol was reduced to 78 $\mathrm{mmol} / \mathrm{l}$ and $60 \mathrm{mmol} / \mathrm{l}$, respectively. For control isotonic solution, mannitol was replaced by D-sorbitol. Osmolarity of all test solutions was checked by freezing point osmometer immediately before experiments.

Collagenase type I was obtained from Gibco (GIBCO TM, Invitrogen Co., Paisley, UK). $\mathrm{CsCl}$ and HEPES were purchased from Amresco Co. (USA). L-glutamic acid, taurine, mannitol and D-sorbitol were obtained from Wuhan Zhongnan Chemical Reagent Co. (Wuhan, China). All other chemicals were purchased from Sigma (Saint Louis, Mo, USA).

\section{Isolation of myocytes}

Single cardiac ventricular myocytes were enzymatically isolated from healthy adult rats (250$300 \mathrm{~g}$, of either sex, Grade II). In brief, rats were anesthetized with $20 \%$ urethane ( $1 \mathrm{~g} / \mathrm{kg}$, i.p.) $20 \mathrm{~min}$ after an intraperitoneal injection of 2000 units of heparin. Hearts were excised rapidly, and retrogradely perfused through the aorta using a modified Langendorff apparatus. The following solutions were applied: 1) Tyrode solution without adding $\mathrm{Ca}^{2+}\left(\mathrm{Ca}^{2+}\right.$-free) for $5 \mathrm{~min}, 2$ ) $\mathrm{Ca}^{2+}$-free Tyrode solution containing $0.2 \mathrm{mg} / \mathrm{ml}$ collagenase type I and $0.5 \mathrm{mg} / \mathrm{ml} \mathrm{BSA}$ for $30 \mathrm{~min}$, and 3) KB solution for the final $5 \mathrm{~min}$. These perfusates were bubbled with $100 \% \mathrm{O}_{2}$ and maintained at $37{ }^{\circ} \mathrm{C}$. The ventricles were cut into small chunks and gently agitated in $\mathrm{KB}$ solution. The cells were filtered through nylon mesh and stored in $\mathrm{KB}$ solution at $4{ }^{\circ} \mathrm{C}$ until use. The study conforms to Hubei Provincial Guide for the Care and Use of Laboratory Animals.

\section{Current recordings}

Currents were recorded from isolated myocytes with similar size using a Multiclamp 700B amplifier (Axon Instruments, USA) by means of whole-cell configuration of the patch-clamp technique. The patch electrodes had resistance of 1.0-1.5 M $\Omega$ when filled with the pipette solution. Capacitance and series resistances were adjusted to obtain minimal contribution of the capacitative transients. An $90 \%$ compensation of the series resistance was usually achieved without ringing. Residual linear leak and capacitance were subtracted by using a P/4 leaksubtract protocol. Currents were filtered at $2 \mathrm{kHz}$, digitized at $10 \mathrm{kHz}$ and stored on a computer hard disk for analysis. Experiments were done at room temperature $\left(22 \pm 2{ }^{\circ} \mathrm{C}\right)$. For the $\mathrm{I}_{\mathrm{NaT}}$ and $\mathrm{I}_{\mathrm{NaP}}$ recording, a single pulse protocol was used from a holding potential (HP) of $-120 \mathrm{mV}$ to $-40 \mathrm{mV}$. The duration of the depolarizing pulse was 300 $\mathrm{ms}$. For the I-V relationship and steady-state activation protocol, currents were elicited by $300 \mathrm{~ms}$ depolarizing pulses applied at $0.5 \mathrm{~Hz}$ from a holding potential of -120 $\mathrm{mV}$, in $5 \mathrm{mV}$ increments between -80 and $+40 \mathrm{mV}$. The steady-state inactivation protocol was from a HP of -120 $\mathrm{mV}$; $50 \mathrm{~ms}$ conditioning prepulses were applied in $5 \mathrm{mV}$ increments between -140 and $-20 \mathrm{mV}$ followed by a 30 $\mathrm{ms}$ test pulse to $-30 \mathrm{mV}$ at $0.5 \mathrm{~Hz}$. For the inactivation recovery protocol, a double-pulse mode was used. The prepulse and the test pulse were all elicited from a HP of $120 \mathrm{mV}$ to $-40 \mathrm{mV}$, and the intervals of the two pulses were between 2 and $100 \mathrm{~ms}$ in $2 \mathrm{~ms}$ increments at $0.5 \mathrm{~Hz}$. For the intermediate inactivation $\left(\mathrm{I}_{\mathrm{IM}}\right)$ protocol, a prepulse was elicited from a HP of $-140 \mathrm{mV}$ to a depolarizing potential of $-20 \mathrm{mV}$ followed by a $20 \mathrm{~ms}$ test pulse with the same depolarizing potential. The depolarizing duration of prepulse was between 12 and $34242 \mathrm{~ms}$ in 15 different increments at $0.2 \mathrm{~Hz}$. The intervals of the prepulse and the test pulse were $20 \mathrm{~ms}$. These measurements were made after a minimal time of $5 \mathrm{~min}$ after rupture of the patch to minimize the contribution of time-dependent shifts of steady-state gating parameter measurements.

\section{Data analysis}

Whole-cell recordings were analyzed using Clampfit 9.0. Sodium currents were defined by subtraction of the currents remaining in $20 \mu \mathrm{mol} / 1$ tetrodotoxin (TTX). The amplitude of $\mathrm{I}_{\mathrm{NaP}}$ was measured after $200 \mathrm{~ms}$ of the 

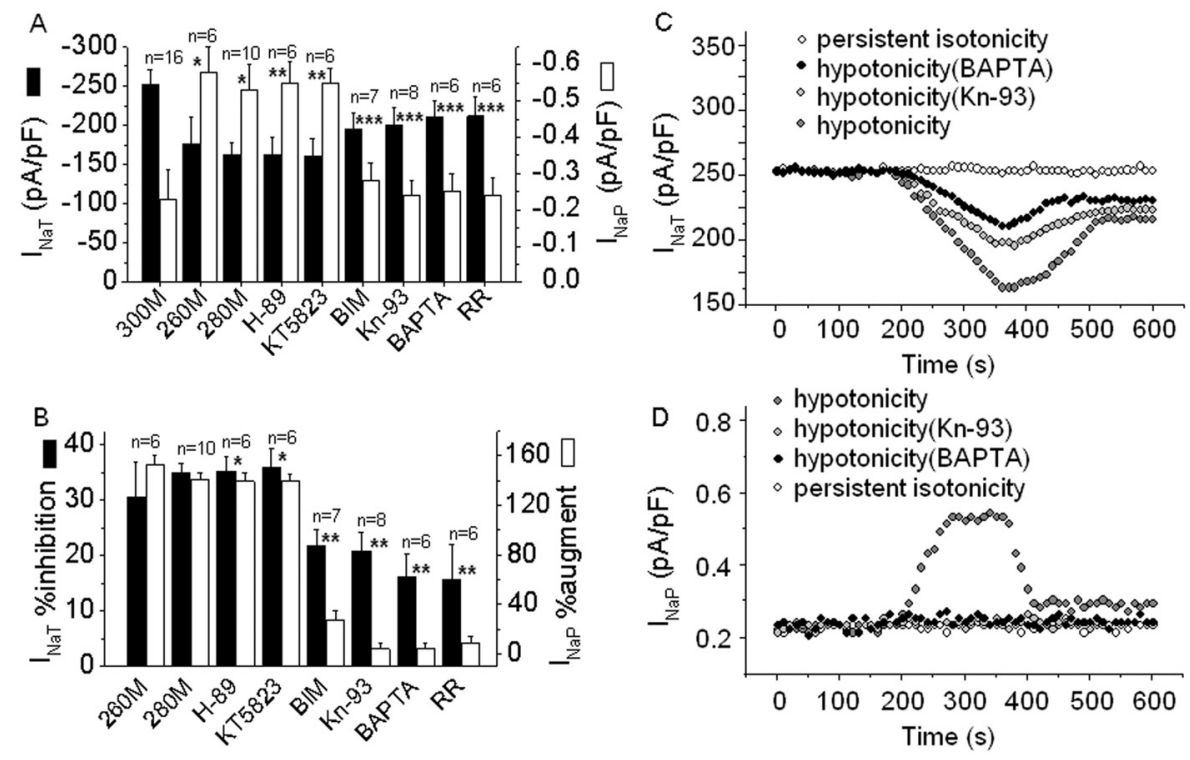

Fig. 1. Effects of hypotonic solution on transient sodium currents $\left(\mathrm{I}_{\mathrm{NaT}}\right)$ and persistent sodium currents ( $\left.\mathrm{I}_{\mathrm{NaP}}\right)$. $\mathrm{H}-89$ dihydrochloride hydrate $(\mathrm{H}-89)$, KT5823, bisindolylmaleimide VI (BIM), $\mathrm{Kn}-93, \mathrm{BAPTA}$ and ruthenium red (RR) were filled into recording pipette solution respectively. The corresponding bars of these drugs represented hypotonic values. A. Amplitudes of $\mathrm{I}_{\text {NaT }}$ and $\mathrm{I}_{\text {Nap. }} * P<0.01$ vs. $300 \mathrm{M}$, $* * P>0.05$ vs. $280 \mathrm{M}, * * P<0.01$ vs. 280 M. B. Percentage inhibition of $I_{\text {NaT }}$ and percentage augment of $\mathrm{I}_{\mathrm{NaP}}$. $* P>0.05$ vs. $280 \mathrm{M}, * * P<0.01$ vs. 280 M. C. Tendency of $I_{\text {NaT }}$ along time. D. Tendency of $I_{\text {Nap }}$ along time. For panels $C$ and $D$, the ventricular myocytes were perfused with isotonic solutions in the first $3 \mathrm{~min}$, with hypotonic solutions in the subsequent $3 \mathrm{~min}$, and reperfused with isotonic solutions in the last several minutes without or with $\mathrm{Kn}-93$ and BAPTAfilled pipette solution. depolarizaton to eliminate the effect of $\mathrm{I}_{\mathrm{NaT}}$. Data from steady-state activation and inactivation relationship of $\mathrm{I}_{\mathrm{NaT}}$ were fitted to the Boltzmann equation: $\mathrm{Y}=1 /\left[1+\exp \left(\mathrm{V}_{\mathrm{m}}\right.\right.$ $\left.-\mathrm{V}_{1 / 2} / \mathrm{k}\right]$, where $V_{m}$ is the membrane potential, $V_{I / 2}$ is the half-activation or half-inactivation potential, and $k$ is the slope factor. For steady-state activation curve, $Y$ stands for the relative conductance. The chord conductance was calculated using the ratio of the currents to their electromotive for potentials in individual current-voltage relationships. Then these conductances were normalized to their individual maximal values. For steady-state inactivation curve, $\mathrm{Y}$ represents the relative current $\left(\mathrm{I}_{\mathrm{NaT}} / \mathrm{I}_{\mathrm{NaT} \text {.Max }}\right)$. Data from the recovery from inactivation were fitted to the exponential function: $\mathrm{I} / \mathrm{Imax}=1-\exp (-$ $t / \tau$ ), where $\tau$ is the recovery time constant. Data from $I_{I M}$ were fitted to the exponential function: $\mathrm{y}=\mathrm{b} \exp (-\mathrm{kx})+\mathrm{a}$, where $b$ is the 'weight', $k$ is the rate constant, and $a$ is the Y-offset constant.

All data were expressed as mean \pm S.D. Statistical significance was estimated by Student's t test or the one-way analysis of variance (ANOVA), as appropriate. When the $\mathrm{F}$ value allowed, Tukey multiple comparisons test was used to compare the groups with control. $\mathrm{P}<0.05$ was considered significant. Figures were plotted by Origin (V7.0, OriginLab Co., MA, USA).

\section{Results}

The effects of hypotonic solution on $I_{N a T}$ and $I_{N a P}$

We found that the membrane capacitance and series resistances did not evidently change when the cardiac myocytes were perfused by hypotonic solution. Thus we neglected the adjustment of them when the bath solutions were changed. To investigate whether mannitol affected sodium currents, we replaced mannitol by D-sorbitol in the isotonic extracellular solution and found there were no significant difference between their effects on the amplitudes of $\mathrm{I}_{\mathrm{NaT}}$ and $\mathrm{I}_{\mathrm{NaP}}$ (data not shown).

In the present research, hypotonic solution suppressed $\mathrm{I}_{\mathrm{NaT}}$ and increased $\mathrm{I}_{\mathrm{NaP}}$ at the same time (Figs 1 and 2). When the isolated ventricular myocytes were perfused by $280 \mathrm{M}$ hypotonic solution, the current density of $\mathrm{I}_{\mathrm{NaT}}$ was decreased from $-249.2 \pm 14.8 \mathrm{pA} / \mathrm{pF}$ to $-162.2 \pm 15.9 \mathrm{pA} / \mathrm{pF}$ and $\mathrm{I}_{\mathrm{NaP}}$ was increased from $-0.22 \pm 0.07 \mathrm{pA} / \mathrm{pF}$ to $-0.53 \pm 0.07 \mathrm{pA} / \mathrm{pF} \quad(\mathrm{n}=10$, both $\mathrm{P}<0.01$ vs. $300 \mathrm{M}$ ), the inhibition ratio of $\mathrm{I}_{\mathrm{NaT}}$ being $34.9 \pm 1.8 \%$. $\mathrm{I}_{\mathrm{NaT}}$ was reverted to $-214.8 \pm 30.6 \mathrm{pA} / \mathrm{pF}$ and $\mathrm{I}_{\mathrm{NaP}}$ to $-0.29 \pm 0.07 \mathrm{pA} / \mathrm{pF}$ after being reperfused by $300 \mathrm{M}$ isotonic solution (Fig. 1). We found similar results when the myocytes were perfused by $260 \mathrm{M}$ hypotonic solution. $260 \mathrm{M}$ hypotonic solution decreased $\mathrm{I}_{\mathrm{NaT}}$ from $-253.4 \pm 23.2 \mathrm{pA} / \mathrm{pF}$ to $-175.6 \pm 35.3 \mathrm{pA} / \mathrm{pF}$ and increased $\mathrm{I}_{\mathrm{NaP}}$ from $-0.23 \pm 0.08 \mathrm{pA} / \mathrm{pF}$ to $-0.58 \pm 0.07 \mathrm{pA} / \mathrm{pF}(\mathrm{n}=10$, both $\mathrm{P}<0.01$ vs. $300 \mathrm{M}$ ), the inhibition ratio of $\mathrm{I}_{\mathrm{NaT}}$ being $30.6 \pm 6.2 \%$ (Fig. 1). We used $280 \mathrm{M}$ hypotonic solution to study I-V relationship, steady-state activation, steadystate inactivation, recovery from inactivation and intermediate inactivation.

Hypotonicity $(280 \mathrm{M})$ only decreased the amplitude of I-V curve, but did not change its shape. The 

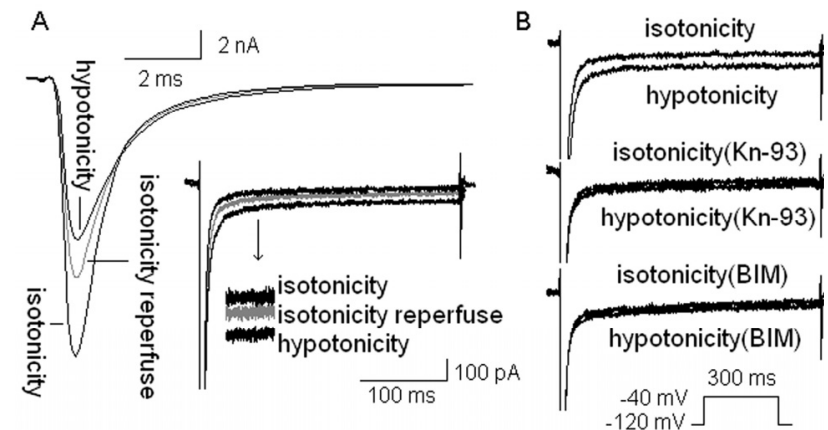

Fig. 2. A. The interconversion between $I_{\mathrm{NaT}}$ and $I_{\mathrm{NaP}}$. The peaks of $I_{\mathrm{NaT}}$ and the fractions of $\mathrm{I}_{\mathrm{NaP}}$ from the same raw current traces were shown on left and right-lower sides on panel A. Hypotonic solution decreased $\mathrm{I}_{\mathrm{NaT}}$ and increased $\mathrm{I}_{\mathrm{NaP}}$ at the same time. Isotonic solution reperfusion (showed as gray traces) reversed the above effects. B. Effects of hypotonic solution on $\mathrm{I}_{\mathrm{NaP}}$. Kn-93 (10 $\mu \mathrm{mol} / \mathrm{l}$, pipette solution) and BIM (1.5 $\mu \mathrm{mol} / \mathrm{l}$, pipette solution) antagonized the hypotonic effects on $\mathrm{I}_{\mathrm{NaP}}$.

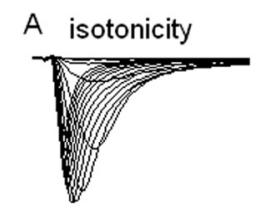

$B$ isotonicity
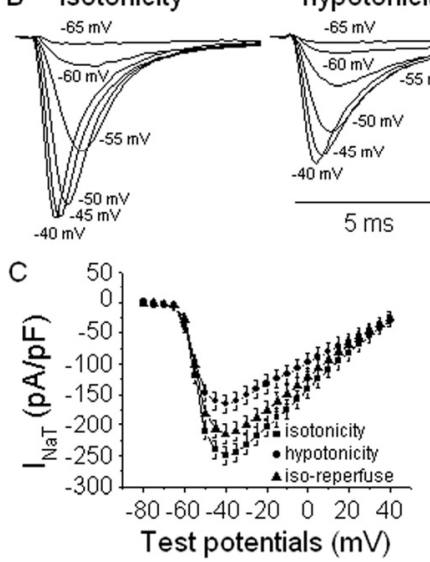

Fig. 3. Effects of hypotonic solution on I-V relationship and steady-state activation. A. Original traces of $\mathrm{I}_{\mathrm{NaT}}$ selected from $-80 \mathrm{mV}$ to $0 \mathrm{mV}$ with $5 \mathrm{mV}$ steps. B. I-V traces from $-65 \mathrm{mV}$ to $-40 \mathrm{mV}$ selected from the original traces on panel A. C. I-V relationship curves of $\mathrm{I}_{\mathrm{NaT}}$. D. Steady-state activation curves. Hypotonic solution decreased $I_{\mathrm{NaT}}$ shown on panels $\mathrm{A}, \mathrm{B}$ and $\mathrm{C}$. Isotonic solution reperfusion reversed the inhibiting effect partly. Panel $D$ shows the absence of significant effects of hypotonic solution on steady-state activation.

threshold potential was $-70 \mathrm{mV}$ and the corresponding potential of the maximum current was $-40 \mathrm{mV}$ (Fig. 3C).

Hypotonicity $(280 \mathrm{M})$ had no significant effect on the steady-state activation $(n=10, P>0.05$ vs. $300 \mathrm{M}$, Table 2, Fig. 3D), but shifted the steady-state inactivation to a more negative membrane potential $(\mathrm{n}=10, \mathrm{P}<0.05 \mathrm{vs}$. $300 \mathrm{M}$ Table 1, Fig. 4C). It revealed that hypotonicity had no significant effect on the activation process, but

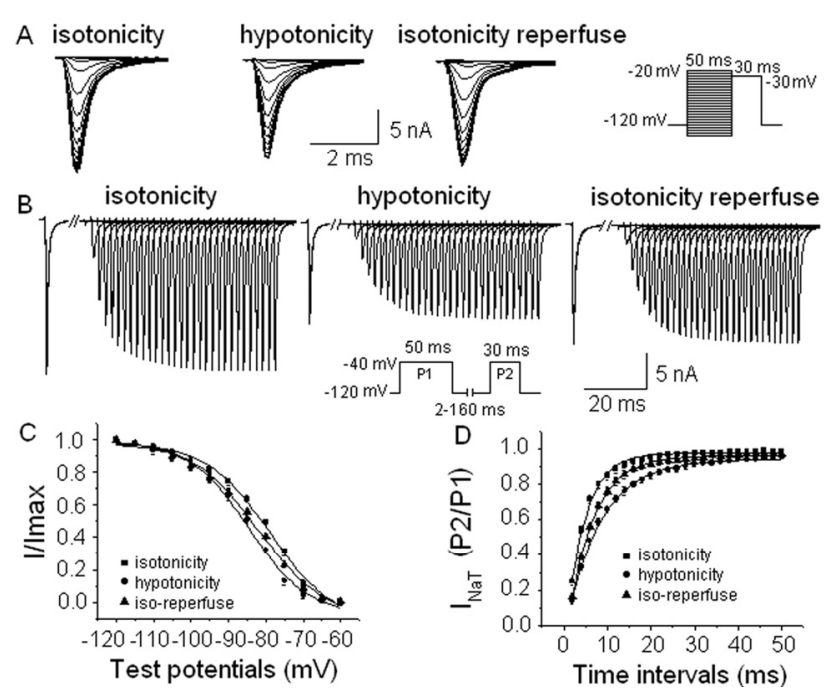

Fig. 4. Effects of hypotonic solution on steady-state inactivation and recovery from inactivation. A. Original $\mathrm{I}_{\mathrm{NaT}}$ traces elicited by test pulses of recording protocol for steady-state inactivation. B. Original $\mathrm{I}_{\mathrm{NaT}}$ elicited by prepulse and test pulses of recording protocol for recovery from inactivation. The $\mathrm{I}_{\mathrm{NaT}}$ amplitudes and tendency were altered by hypotonic solution. Isotonic reperfusion reversed it partly. C. Steady-state inactivation curves. Hypotonic solution shifted steady-state inactivation curve to the left significantly, and isotonic reperfusion reversed it partly shown on panel C. D. Curves of recovery from inactivation. Hypotonic solution shifted it to the right significantly and prolonged recovery time.

had significant effect on the inactivation process. Hypotonicity delayed the inactivation process and increased the time constant ( $\tau$ value, $\mathrm{n}=10, \mathrm{P}<0.01$ vs. $300 \mathrm{M})$ for recovery from inactivation significantly, indicating that recovery was slowed (Table 1, Fig. 4D).

We also studied the $\mathrm{I}_{\mathrm{IM}}$ of sodium channels and found hypotonicity significantly enhanced the fraction of channels undergoing $\mathrm{I}_{\mathrm{IM}}$. The 'weight' (b) and rate constant $(\mathrm{k})$ were increased and the amplitude of a was decreased significantly $(n=6$, Table 2 , Fig. 6).

The effects of TRPV4 and intracellular signal transduction system

We investigated whether TRPV4 and intracellular signal transduction system participated in the hypotonicity-adjusting process on sodium currents. H-89 dihydrochloride hydrate (H-89, selective inhibitor of PKA), KT5823 (selective inhibitor of PKG), bisindolylmaleimide VI (BIM, selective inhibitor of PKC), Kn-93 (selective inhibitor of $\mathrm{Ca} / \mathrm{CaMKII}$ ) and BAPTA $\left(\mathrm{Ca}^{2+}\right.$-chelator, used with $\mathrm{Ca}^{2+}$-free and EGTAfree pipette solution) were filled into recording pipette solution, respectively (for $\mathrm{I}_{\mathrm{IM}}$ research, the Kn-93 was added to extracellular perfusing solution). Ruthenium red (RR, inhibitor of TRPV4) was used to incubate the single 


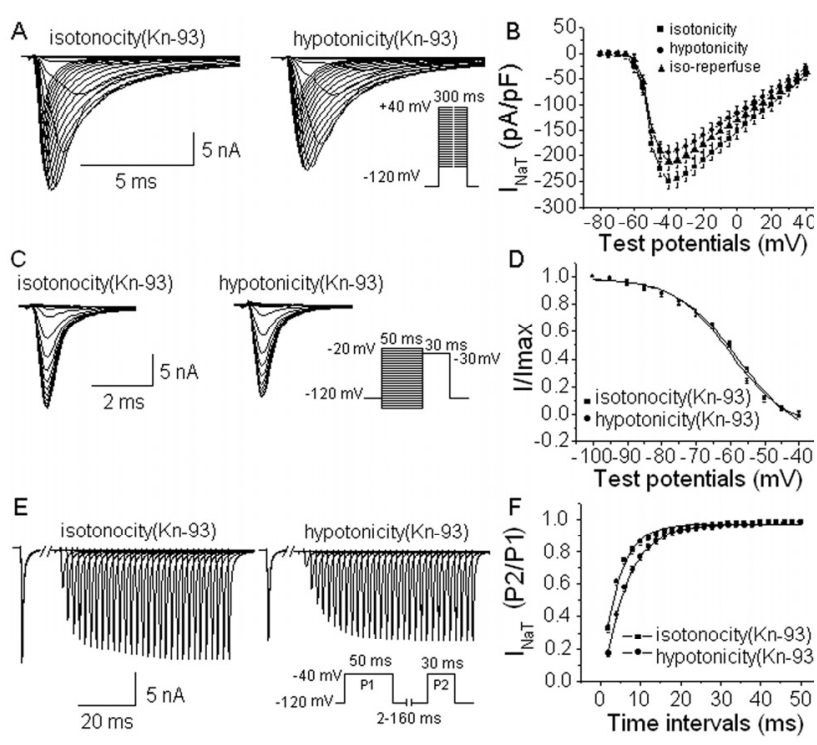

Fig. 5. $\mathrm{Kn}-93(10 \mu \mathrm{mol} / \mathrm{l}$ in pipette solution) antagonized the effects of hypotonic solution on I-V relationship, steady-state inactivation and recovery from inactivation. A. Original current traces. B. I-V curves of $\mathrm{I}_{\mathrm{NaT}}$. $\mathrm{I}_{\mathrm{NaT}}$ amplitudes were decreased by hypotonic solution, but in lower percentage inhibition versus pure hypotonicity. C. Original $\mathrm{I}_{\mathrm{NaT}}$ traces elicited by test pulses of recording protocol for steady-state inactivation. D. Steady-state inactivation curves. Steady-state inactivation curves were unaltered by hypotonic solution with Kn-93. E. Original $I_{\mathrm{NaT}}$ elicited by prepulse and test pulses of recording protocol for recovery from inactivation with $10 \mu \mathrm{mol} / \mathrm{l} \mathrm{Kn-93}$ in pipette solution. F. Curves of recovery from inactivation. Hypotonic solution with $\mathrm{Kn}-93$ shifted them to the right in smaller amplitude versus pure hypotonicity.

myocytes for $3 \mathrm{~min}$ before recording. A single pulse from $-120 \mathrm{mV}$ to $-40 \mathrm{mV}$ was used to record $\mathrm{I}_{\mathrm{NaT}}$ and $\mathrm{I}_{\mathrm{NaP}}$.

During hypotonicity, RR $(10 \mu \mathrm{mol} / \mathrm{l})$ diminished the inhibition ratio of $\mathrm{I}_{\mathrm{NaT}}$ to $15.8 \pm 6.1 \%(\mathrm{n}=6, \mathrm{P}<0.01$ vs. control, $34.9 \pm 1.8 \%$ ) and inhibited $\mathrm{I}_{\mathrm{NaP}}$ to $-0.24 \pm 0.05$ $\mathrm{pA} / \mathrm{pF} \quad(\mathrm{n}=6, \mathrm{P}<0.01$ vs. control, $-0.53 \pm 0.07 \mathrm{pA} / \mathrm{pF})$. Kn-93 $(10 \mu \mathrm{mol} / \mathrm{l})$ diminished the inhibition ratio of $\mathrm{I}_{\mathrm{NaT}}$ to $20.8 \pm 3.4 \%$ ( $\mathrm{n}=8, \mathrm{P}<0.01$ vs. control, $34.9 \pm 1.8 \%$ ) and inhibited $\mathrm{I}_{\mathrm{NaP}}$ to $-0.24 \pm 0.04 \mathrm{pA} / \mathrm{pF} \quad(\mathrm{n}=8, \mathrm{P}<0.01$ vs. control, $-0.53 \pm 0.07 \mathrm{pA} / \mathrm{pF})$. BIM $(1.5 \mu \mathrm{mol} / \mathrm{l})$ diminished the inhibition ratio of $\mathrm{I}_{\mathrm{NaT}}$ to $21.8 \pm 3.0 \%(\mathrm{n}=7, \mathrm{P}<0.01$ vs. control, $34.9 \pm 1.8 \%$ ), and inhibited $\mathrm{I}_{\mathrm{NaP}}$ to $-0.28 \pm 0.05$ $\mathrm{pA} / \mathrm{pF} \quad(\mathrm{n}=7, \mathrm{P}<0.01$ vs. control, $-0.53 \pm 0.07 \mathrm{pA} / \mathrm{pF})$. BAPTA ( $1 \mathrm{mmol} / \mathrm{l})$ diminished the inhibition ratio of $\mathrm{I}_{\mathrm{NaT}}$ to $16.2 \pm 4.0 \%$ ( $\mathrm{n}=6, \mathrm{P}<0.01$ vs. control, $34.9 \pm 1.8 \%$ ), and inhibited $\mathrm{I}_{\mathrm{NaP}}$ to $-0.25 \pm 0.05 \mathrm{pA} / \mathrm{pF} \quad(\mathrm{n}=6, \mathrm{P}<0.01$ vs. control, $-0.53 \pm 0.07 \mathrm{pA} / \mathrm{pF}$ ) (Fig. 1). These results revealed that TRPV4 and $\mathrm{Ca}^{2+}, \mathrm{Ca} / \mathrm{CaMKII}$ and PKC participated in the adjusting process. We further investigated the effects of BIM and Kn-93 on I-V relationship, steady-state activation, steady-state inactivation, recovery from inactivation. Both of the drugs inhibited the effects of hypotonicity on them (Tables 1 and 2, Figs 2 and 5). Furthermore, Kn-93 also inhibited the effects of hypotonicity on $\mathrm{I}_{\mathrm{IM}}$ (Fig. 6). Additional experiments using $\mathrm{Kn}-92$ showed that in contrast to Kn-93, it failed to inhibit the effects of hypotonicity on sodium currents (data not shown).

H-89 $(1 \mu \mathrm{mol} / \mathrm{l})$ and KT5823 $(2 \mu \mathrm{mol} / \mathrm{l}) \mathrm{had}$ no significant effects on $\mathrm{I}_{\mathrm{NaT}}$ and $\mathrm{I}_{\mathrm{NaP}}$ during hypotonicity, suggesting PKA and PKG did not participate in the adjusting process (Fig. 1).

\section{Discussion}

TRPV4, a $\mathrm{Ca}^{2+}$-permeable cation channel in the transient receptor potential (TRP) channels family, has been cloned from the rat, mouse, human and chicken. The TRPV4 channel is widely expressed in mammalian tissues, including heart, sensory neurons, etc (Guler et al. 2002, Inoue et al. 2006, Plant and Strotmann 2007). Activation of TRPV4 channel by hypotonic solution increases intracellular $\mathrm{Ca}^{2+}$ concentration (Strotmann et al. 2003, Alessandri-Haber et al. 2003, Inoue et al. 2006), which can activate $\mathrm{Ca} / \mathrm{CaMKII}$ and PKC. Thus TRPV4 may play an important role in $\mathrm{Ca}^{2+}$ signaling during hypotonic stimulation (Chen et al. 2008a,b). In the present study, ruthenium red, BAPTA, KN-93 and BIM diminished the hypotonic effects on the ventricular myocytes, revealing the possible role of TRPV4 during hypotonic stimulation. According to previous studies, many intracellular signals are involved in the hypotonic swelling process (Mongin and Orlov 2001, Stutzin and Hoffmann 2006, Hoffmann and Pedersen 2006). Our experiments revealed that $\mathrm{Ca}^{2+}, \mathrm{PKC}$ and $\mathrm{Ca} / \mathrm{CaMKII}$ participated in the hypotonic regulating process on sodium channels. Nevertheless, the inhibitors of the first three did not completely eliminate the hypotonic effects on $\mathrm{I}_{\mathrm{NaT}}$, suggesting that there were also involved other mechanisms.

Our study showed that hypotonicity decreased $\mathrm{I}_{\mathrm{NaT}}$ and increased $\mathrm{I}_{\mathrm{NaP}}$ simultaneously. The two currents were reverted after being reperfused with $300 \mathrm{M}$ isotonic solution. The changes of $\mathrm{I}_{\mathrm{NaT}}$ were accompanied by the opposite changes of $\mathrm{I}_{\mathrm{NaP}}$. It means that when $\mathrm{I}_{\mathrm{NaT}}$ was decreased, $\mathrm{I}_{\mathrm{NaP}}$ was increased and vice versa. This demonstrated the existence of an interconversion between $\mathrm{I}_{\mathrm{NaT}}$ and $\mathrm{I}_{\mathrm{NaP}}$ during hypotonicity (Fig. 1C, 1D and 2A). The interconversion was reversed by RR, BIM, Kn-93 and BAPTA, indicating that TRPV4 and intracellular $\mathrm{Ca}^{2+}, \mathrm{PKC}$ and $\mathrm{Ca} / \mathrm{CaMKII}$ systems participated in the 
Table 1. Effects of hypotonic solution on steady-state activation, inactivation and recovery from inactivation.

\begin{tabular}{lllllllll}
\hline \multirow{2}{*}{ Treatments } & \multicolumn{3}{c}{ Steady-state activation } & & \multicolumn{2}{c}{ Steady-state inactivation } & \multicolumn{2}{c}{ Inactivation recovery } \\
& \multicolumn{1}{c}{$\mathbf{V}_{\mathbf{1} / \mathbf{2}}$} & \multicolumn{1}{c}{$\mathbf{k}$} & $\mathbf{n}$ & \multicolumn{1}{c}{$\mathbf{V}_{\mathbf{1} / \mathbf{2}}$} & \multicolumn{1}{c}{$\mathbf{k}$} & $\mathbf{n}$ & $\boldsymbol{\tau}$ & $\mathbf{n}$ \\
\hline $300 \mathrm{M}$ & $-53.8 \pm 2.2$ & $3.29 \pm 0.25$ & 10 & $-78.7 \pm 2.2$ & $-8.55 \pm 0.33$ & 10 & $4.40 \pm 0.25$ & 10 \\
$280 \mathrm{M}$ & $-55.2 \pm 1.9^{*}$ & $3.68 \pm 0.30^{*}$ & 10 & $-84.3 \pm 2.5 \dagger$ & $-7.70 \pm 0.41 \dagger$ & 10 & $8.02 \pm 0.23 \dagger$ & 10 \\
$300 \mathrm{Mr}$ & $-54.4 \pm 1.4$ & $3.57 \pm 0.29$ & 10 & $-81.9 \pm 3.2$ & $-9.05 \pm 0.45$ & 10 & $5.94 \pm 0.24$ & 10 \\
& & & & & & & & \\
$300 M+K n-93 p$ & $-51.6 \pm 2.0$ & $3.03 \pm 0.21$ & 8 & $-77.8 \pm 2.0$ & $-8.88 \pm 0.25$ & 8 & $4.42 \pm 0.31$ & 8 \\
$280 M+K n-93 p$ & $-52.5 \pm 2.0 \S$ & $3.20 \pm 0.25 \S$ & 8 & $-79.9 \pm 1.8 \S$ & $-8.29 \pm 0.18 \S$ & 8 & $5.89 \pm 0.22 \|$ & 8 \\
$300 M+B I M p$ & $-51.9 \pm 2.0$ & $3.20 \pm 0.23$ & 7 & $-78.0 \pm 2.2$ & $-8.75 \pm 0.30$ & 7 & $4.45 \pm 0.40$ & 7 \\
$280 M+B I M p$ & $-52.3 \pm 2.3 \#$ & $3.35 \pm 0.27 \#$ & 7 & $-79.2 \pm 2.4 \#$ & $-8.18 \pm 0.23 \#$ & 7 & $5.90 \pm 0.36 \|$ & 7 \\
\hline
\end{tabular}

* $P>0.05$ vs. $300 \mathrm{M},+P<0.05$ vs. $300 \mathrm{M}, \neq P<0.01$ vs. $300 \mathrm{M}, \S P>0.05$ vs. $300 \mathrm{M}+\mathrm{Kn}-93, \| P<0.01$ vs. $280 \mathrm{M}$, \# $P>0.05$ vs. $300 \mathrm{M}+\mathrm{BIM}, \mathrm{p}=$ drug was added into pipette solution, $\mathrm{r}=$ reperfused.

above-mentioned hypotonic modifications.

The previous studies of our group have demonstrated the interconversion between $\mathrm{I}_{\mathrm{NaT}}$ and $\mathrm{I}_{\mathrm{NaP}}$ during redox reaction (Luo et al. 2007, Wang et al. 2007). Based on recent studies, we assume that $I_{\mathrm{NaT}}$ and $\mathrm{I}_{\mathrm{NaP}}$ may be two different gating modes of sodium channels which can exhibit interconversion modulated by some factors. For instance, it is probable that some sodium channels are switched to $\mathrm{I}_{\mathrm{NaP}}$-charged gating mode resulting in more $\mathrm{I}_{\mathrm{NaP}}$ and less $\mathrm{I}_{\mathrm{NaT}}$. The phenomenon may be induced by the phosphorylation of some structural domains of sodium channels (Qu et al. 1996, Luo et al. 2007, Wang et al. 2007). Of course, the real mechanisms of the hypotonicity-induced interconversion between $\mathrm{I}_{\mathrm{NaT}}$ and $\mathrm{I}_{\mathrm{NaP}}$ need to be interpreted by more detailed studies.

In this study, hypotonicity shifted steady-state inactivation to a more negative potential and prolonged the recovery time from inactivation. These results indicate that the availability of sodium channels is reduced during depolarizing. At the same potential, hypotonicity transforms more sodium channels into inactivation state and prolongs the refractory period of cardiocytes for reactivation. The downward shift of $\mathrm{I}_{\mathrm{IM}}$ curve reveals the augmentation of inactivation, further suggesting that when $\mathrm{I}_{\mathrm{NaP}}$ increases, $\mathrm{I}_{\mathrm{NaT}}$ decreases simultaneously. Since sodium currents play important roles in ventricular muscle electric activity, we can conclude that hypotonicity may inhibit the excitability and excitation conductability of ventricular myocytes.

Solute flux pathways activated by hypotonic swelling permits intracellular osmotic materials efflux
Table 2. Effects of hypotonic solution on intermediate inactivation $\left(\mathrm{I}_{\mathrm{IM}}\right)$.

\begin{tabular}{|c|c|c|c|c|}
\hline \multirow[t]{2}{*}{ Treatments } & \multicolumn{4}{|c|}{ Intermediate inactivation $\left(\mathrm{I}_{\mathrm{IM}}\right)$} \\
\hline & $\mathrm{k}\left(\times 10^{-4} \mathrm{~ms}^{-1}\right)$ & b & $\mathbf{a}$ & $\mathbf{n}$ \\
\hline $300 M$ & $0.68 \pm 0.07$ & $0.19 \pm 0.04$ & $0.78 \pm 0.05$ & 6 \\
\hline $280 M$ & $1.12 \pm 0.08^{*}$ & $0.31 \pm 0.05^{*}$ & $0.63 \pm 0.04^{*}$ & 6 \\
\hline $280 M+K n-93 b^{\prime}$ & $0.70 \pm 0.08 \dagger$ & $0.24 \pm 0.04 \dagger$ & $0.71 \pm 0.04 \dagger$ & 6 \\
\hline
\end{tabular}

$* P<0.05$ vs. $300 \mathrm{M},+P<0.05$ vs. $280 \mathrm{M}, \mathrm{b}^{\prime}=\mathrm{Kn}-93$ was added to bath solution.

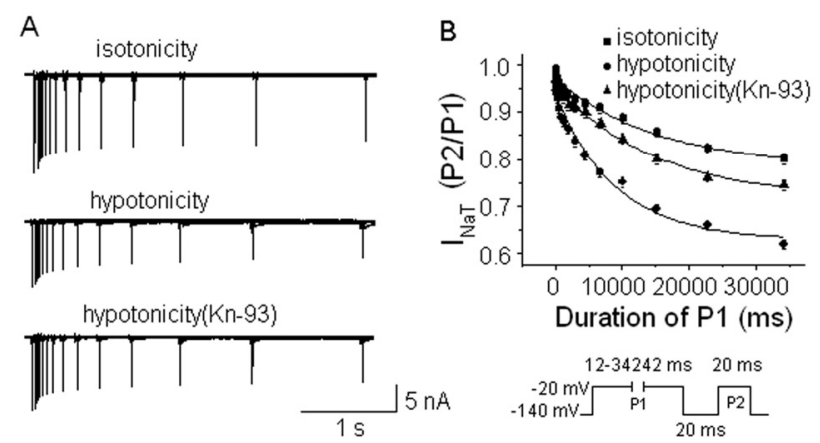

Fig. 6. Effects of hypotonic solution on intermediate inactivation ( $\left.\mathrm{I}_{\mathrm{IM}}\right)$. A. Original current traces of $\mathrm{I}_{\mathrm{NaT}}$ elicited by prepulse and test pulses of recording protocol for recording $\mathrm{I}_{\mathrm{IM}}$. B. $\mathrm{I}_{\mathrm{IM}}$ curves. Hypotonic solution increased the amount of accumulating $\mathrm{I}_{\mathrm{IM}}$ versus isotonic, and the effect was reversed by $\mathrm{Kn}-93(10 \mu \mathrm{mol} / \mathrm{l}$ in perfused solution).

and restricts extracellular osmotic materials inflow, tending to restore cell volume to its original size (Vandenberg et al. 1996). $\mathrm{Na}^{+}$inflow may be, without exception, restricted and $\mathrm{I}_{\mathrm{NaT}}$ suppressed. Our experimental results are consistent with this deduction. 
Besides, the suppression of $\mathrm{I}_{\mathrm{NaT}}$ may result from a different mechanism. $\mathrm{I}_{\mathrm{NaP}}$ is enhanced by some factors and drugs such as ischemia, hypoxia, redox reaction, $\mathrm{H}_{2} \mathrm{O}_{2}$, NO, GSSG and veratridine ( $\mathrm{Ju}$ et al. 1996, Hammarstrom and Gage 1999, Ma et al. 2005, Saint 2006, Luo et al. 2007, Wang et al. 2007). Some studies have revealed that intracellular $\mathrm{Na}^{+}$concentration $\left(\left[\mathrm{Na}^{+}\right]_{\mathrm{i}}\right)$ increases during myocardial ischemia due to persistent $\mathrm{Na}^{+}$inflow $\left(\mathrm{I}_{\mathrm{NaP}}\right)$ (Williams et al. 2007). The increase of intracellular $\left[\mathrm{Na}^{+}\right]$may facilitate hypotonic swelling during the initial stage of myocardial ischemia $(\mathrm{Qu}$ et al. 1996). The increase of intracellular $\left[\mathrm{Na}^{+}\right]$decreases the $\left[\mathrm{Na}^{+}\right]$gradient difference between both sides of the cell membrane. Consequently, the $\mathrm{I}_{\mathrm{NaT}}$ would also be suppressed.

Why $\mathrm{I}_{\mathrm{NaP}}$ is increased under these conditions? It is very likely that the adjusting mechanisms of intracellular signal transduction are activated during hypotonicity. Previous papers have demonstrated that intracellular PKC and $\mathrm{Ca}^{2+} / \mathrm{CaMKII}$ systems are related to $\mathrm{I}_{\mathrm{NaP}}$ (Qu et al. 1996, Murray et al. 1997, Kim et al. 2004, Wagner et al. 2006). PKC activates the phosphorylation of serine and threonine located in the inactivation gate of sodium channels protein which leads to inactivation loss and increases $\mathrm{I}_{\mathrm{NaP}}(\mathrm{Qu}$ et al. 1996, Murray et al. 1997). CaM binding to some motif at the $\mathrm{C}$ termination of sodium channels probably adjusts $\mathrm{I}_{\mathrm{NaP}}$ via $\mathrm{Ca}^{2+} / \mathrm{CaMKII}$ (Kim et al. 2004, Wagner et al. 2006). The present study revealed that BIM, Kn-93 and BAPTA weakened the $\mathrm{I}_{\mathrm{NaP}}$ induced by hypotonicity. These results not only indicate that $\mathrm{PKC}$ and $\mathrm{Ca} / \mathrm{CaMKII}$ participate in the hypotonicity-adjusting process on $\mathrm{I}_{\mathrm{NaP}}$, but also verify that intracellular $\mathrm{Ca}^{2+}$ is correlated to $\mathrm{I}_{\mathrm{NaP}}$. The enhanced $\mathrm{I}_{\mathrm{NaP}}$ prolongs action potential duration, resulting in $\mathrm{LQT}_{3}$ symptom and other arrhythmia (Noble and Noble 2006). $\mathrm{I}_{\mathrm{NaP}}$ increases intracellular $\left[\mathrm{Na}^{+}\right]$and provokes reverse $\mathrm{Na}^{+} / \mathrm{Ca}^{2+}$ exchange which induces intracellular $\mathrm{Ca}^{2+}$ overload (Williams et al. 2007). $\mathrm{I}_{\mathrm{NaP}}$ and $\mathrm{Ca}^{2+}$ overload are important agents causing myocardial ischemia diseases and are related to arrhythmia (Noble and Noble 2006). Consequently, the blockade of $I_{\mathrm{NaP}}$ would contribute to alleviation of ischemia damage. All these experimental results may provide new perspectives for treating myocardial ischemia diseases.

In conclusion, we demonstrated that hypotonicity decreases $\mathrm{I}_{\mathrm{NaT}}$ while $\mathrm{I}_{\mathrm{NaP}}$ increases simultaneously with an interconversion between them, these effects being reversible. TRPV4 and intracellular $\mathrm{Ca}^{2+}$, PKC and $\mathrm{Ca} / \mathrm{CaMKII}$ participate in the hypotonic modifications of sodium currents in rat ventricular myocytes.

\section{Conflict of Interest}

There is no conflict of interest.

\section{Acknowledgements}

This work was supported by the National Natural Science Foundation of China (No.30670764) and the Key Scientific Research Program of Educational Bureau of Hubei Province (No. Z200511002).

\section{References}

ANTZELEVITCH C, BELARDINELLI L: The role of sodium channel current in modulating transmural dispersion of repolarization and arrhythmogenesis. J Cardiovasc Electrophysiol 17 (Suppl 1): S79-S85, 2006.

CHEN L, LIU C, LIU L: Changes in osmolality modulate voltage-gated calcium channels in trigeminal ganglion neurons. Brain Res 1208: 56-66, 2008a.

CHEN L, LIU C, LIU L: The modulation of voltage-gated potassium channels by anisotonicity in trigeminal ganglion neurons. Neuroscience 154: 482-495, 2008b.

DIAZ RJ, ARMSTRONG SC, BATTHISH M, BACKX PH, GANOTE CE, WILSON GJ: Enhanced cell volume regulation: a key protective mechanism of ischemic preconditioning in rabbit ventricular myocytes. $\mathrm{J} \mathrm{Mol} \mathrm{Cell}$ Cardiol 35: 45-58, 2003.

ALESSANDRI-HABER N, YEH JJ, BOYD AE, PARADA CA, CHEN X, REICHLING DB, LEVINE JD: Hypotonicity induces TRPV4-mediated nociception in rat. Neuron 39: 497-511, 2003.

GOLDIN AL: Evolution of voltage-gated $\mathrm{Na}^{+}$channels. J Exp Biol 205: 575-584, 2002.

GULER AD, LEE H, IIDA T, SHIMIZU I, TOMINAGA M, CATERINA M: Heat-evoked activation of the ion channel, TRPV4. J Neurosci 22: 6408-6414, 2002.

HAMMARSTROM AK, GAGE PW: Nitric oxide increases persistent sodium current in rat hippocampal neurons. J Physiol Lond 520: 451-461, 1999. 
HIRAOKA M, KAWANO S, HIRANO Y, FURUKAWA T: Role of cardiac chloride currents in changes in action potential characteristics and arrhythmias. Cardiovasc Res 40: 23-33, 1998.

HOFFMANN EK, PEDERSEN SF: Sensors and signal transduction pathways in vertebrate cell volume regulation. Contrib Nephrol 152: 54-104, 2006.

INOUE R, JENSEN LJ, SHI J, MORITA H, NISHIDA M, HONDA A, ITO Y: Transient receptor potential channels in cardiovascular function and disease. Circ Res 99: 119-131, 2006.

JANSE MJ, WIT AL: Electrophysiological mechanisms of ventricular arrhythmias resulting from myocardial ischemia and infarction. Physiol Rev 69: 1049-1169, 1989.

JENNINGS RB, REIMER KA, STEENBERGEN C: Myocardial ischemia revisited. The osmolar load, membrane damage, and reperfusion. J Mol Cell Cardiol 18: 769-780, 1986.

JU YK, SAINT DA, GAGE PW: Hypoxia increases persistent sodium current in rat ventricular myocytes. $J$ Physiol Lond 497: 337-347, 1996.

KAWATA H, KAWAGOE K, TATEYAMA I: Effects of osmolarity change on the excitation-contraction coupling of bullfrog ventricle. Jpn J Physiol 24: 587-603, 1974.

KIM J, GHOSH S, LIU H, TATEYAMA M, KASS RS, PITT GS: Calmodulin mediates $\mathrm{Ca}^{2+}$ sensitivity of sodium channels. J Biol Chem 279: 45004-45012, 2004.

KOCIC I: Modulators of ion channels activated by hypotonic swelling in cardiomyocytes: new perspectives for pharmacological treatment of life-threatening arrhythmias. Curr Med Chem Cardiovasc Hematol Agents 3: 333-339, 2005.

KOCIC I, HIRANO Y, HIRAOKA M: Ionic basis for membrane potential changes induced by hypoosmotic stress in guinea-pig ventricular myocytes. Cardiovasc Res 51: 59-70, 2001.

LUO A, MA J, ZHANG P, ZHOU H, Wang W: Sodium channel gating modes during redox reaction. Cell Physiol Biochem 19: 9-20, 2007.

MA JH, LUO AT, ZHANG PH: Effect of hydrogen peroxide on persistent sodium current in guinea pig ventricular myocytes. Acta Pharmacol Sin 26: 828-834, 2005.

MONGIN AA, ORLOV SN: Mechanisms of cell volume regulation and possible nature of the cell volume sensor. Pathophysiology 8: 77-88, 2001.

MURRAY KT, HU NN, DAW JR, SHIN HG, WATSON MT, MASHBURN AB, GEORGE AL JR: Functional effects of protein kinase $\mathrm{C}$ activation on the human cardiac $\mathrm{Na}^{+}$channel. Circ Res 80: 370-376, 1997.

NOBLE D, NOBLE PJ: Late sodium current in the pathophysiology of cardiovascular disease: consequences of sodium-calcium overload. Heart 92: iv1-iv5, 2006.

PLANT TD, STROTMANN R: TRPV4. Handb Exp Pharmacol 179: 189-205, 2007.

QU Y, ROGERS JC, TANADA TN, CATTERALL WA, SCHEUER T: Phosphorylation of S1505 in the cardiac $\mathrm{Na}^{+}$ channel inactivation gate is required for modulation by protein kinase C. J Gen Physiol 108: 375-379, 1996.

SAINT DA: The role of the persistent $\mathrm{Na}^{+}$current during cardiac ischemia and hypoxia. $J$ Cardiovasc Electrophysiol 17 (Suppl 1): S96-S103, 2006.

SONG Y, SHRYOCK JC, WAGNER S, MAIER LS, BELARDINELLI L: Blocking late sodium current reduces hydrogen peroxide-induced arrhythmogenic activity and contractile dysfunction. $J$ Pharmacol Exp Ther 318: 214-222, 2006.

SOROTA S: Swelling-induced chloride-sensitive current in canine atrial cells revealed by whole-cell patch-clamp method. Circ Res 70: 679-687, 1992.

STROTMANN R, SCHULTZ G, PLANT TD: $\mathrm{Ca}^{2+}$-dependent potentiation of the nonselective cation channel TRPV4 is mediated by a C-terminal calmodulin binding site. J Biol Chem 278: 26541-26549, 2003.

STUTZIN A, HOFFMANN EK: Swelling-activated ion channels: functional regulation in cell-swelling, proliferation and apoptosis. Acta Physiol (Oxf) 187: 27-42, 2006.

TRANUM-JENSEN J, JANSE MJ, FIOLET WT, KRIEGER WJ, D'ALNONCOURT CN, DURRER D: Tissue osmolality, cell swelling, and reperfusion in acute regional myocardial ischemia in the isolated porcine heart. Circ Res 49: 364-381, 1981.

VANDENBERG JI, REES SA, WRIGHT AR, POWELL T: Cell swelling and ion transport pathways in cardiac myocytes. Cardiovasc Res 32: 85-97, 1996. 
WAGNER S, DYBKOVA N, RASENACK EC, JACOBSHAGEN C, FABRITZ L, KIRCHHOF P, MAIER SK, ZHANG T, HASENFUSS G, BROWN JH, BERS DM, MAIER LS: $\mathrm{Ca}^{2+} /$ calmodulin-dependent protein kinase II regulates cardiac $\mathrm{Na}^{+}$channels. J Clin Invest 116: 3127-3138, 2006.

WANG GL, WANG GX, YAMAMOTO S, YE L, BAXTER H, HUME JR, DUAN D: Molecular mechanisms of regulation of fast-inactivating voltage-dependent transient outward $\mathrm{K}^{+}$current in mouse heart by cell volume changes. J Physiol Lond 568: 423-443, 2005.

WANG W, MA J, ZHANG P, LUO A: Redox reaction modulates transient and persistent sodium current during hypoxia in guinea pig ventricular myocytes. Pflügers Arch 454: 461-475, 2007.

WILLIAMS IA, XIAO XH, JU YK, ALLEN DG: The rise of $\left[\mathrm{Na}^{+}\right]_{\mathrm{i}}$ during ischemia and reperfusion in the rat heartunderlying mechanisms. Pflügers Arch 454: 903-912, 2007. 